\title{
Application of microwave heating in the preparation of functionalized activated carbons
}

\author{
Małgorzata Gil ${ }^{1}$ (D) Sylwia Pasieczna-Patkowska ${ }^{2} \cdot$ Piotr Nowicki $^{3}$
}

Received: 4 December 2018 / Revised: 14 January 2019 / Accepted: 18 January 2019 / Published online: 23 January 2019

(c) The Author(s) 2019

\begin{abstract}
A series of modified carbonaceous materials has been obtained via nitrogenation, oxidation and thermal treatment of peatbased activated carbons with the use of microwave heating. In order to obtain materials characterised by diverse functional groups content, both in terms of the type and quantity, the starting material was subjected to four different treatment: (1) oxidation with nitric acid followed by heat treatment at $600^{\circ} \mathrm{C},(2)$ oxidation with hydrogen peroxide followed by heat treatment at $600{ }^{\circ} \mathrm{C}$, (3) annealing in nitrogen atmosphere at $900{ }^{\circ} \mathrm{C}$ and (4) impregnation with urea followed by heat treatment at $800^{\circ} \mathrm{C}$. All the materials under investigation were characterised by elementary analysis, surface area measurements, estimation of the number of surface functional groups as well as by thermal analysis and photoacoustic and mass spectroscopy. Depending on the procedure of modification, the final products were activated carbons of medium developed surface area ranging from 582 to $657 \mathrm{~m}^{2} / \mathrm{g}$, showing basic or intermediate acidic-basic character of the surface and different content of surface functional groups varying from 0.57 to $1.28 \mathrm{mmol} / \mathrm{g}$. Based on thermal analysis it was shown, that sample annealed in nitrogen atmosphere is the most thermally stable material. In turn, according to the results obtained both from photoacoustic spectroscopy and mass spectroscopy, samples subjected to oxidation with $\mathrm{HNO}_{3}$ or $\mathrm{H}_{2} \mathrm{O}_{2}$ followed by heat treatment with using of microwave radiation are characterised by the highest content of oxygen functional groups.
\end{abstract}

Keywords Activated carbons $\cdot$ Nitrogenation $\cdot$ Oxidation $\cdot$ Microwave heating $\cdot$ Thermal analysis $\cdot$ Photoacoustic spectroscopy

\section{Introduction}

In recent time, much attention has been devoted to modified carbonaceous materials because of a huge spectrum of their applications in various branches of industry as well as everyday life. Such materials can be used not only as adsorbents of gaseous and liquid impurities, but also as catalyst, catalysts supports as well as electrode materials for

Małgorzata Gil

malgorzata.gil@poczta.umcs.lublin.pl

1 Laboratory of Optical Fibers Technology, Faculty of Chemistry, Maria Curie-Sklodowska University, Maria Curie-Sklodowska Sq. 3, 20-031 Lublin, Poland

2 Department of Chemical Technology, Faculty of Chemistry, Maria Curie-Sklodowska University, Maria Curie-Sklodowska Sq. 3, 20-031 Lublin, Poland

3 Laboratory of Applied Chemistry, Faculty of Chemistry, Adam Mickiewicz University in Poznań, Umultowska Street 89b, 61-614 Poznań, Poland electrochemical capacitors and lithium-ion batteries (Huang et al. 2006; Severa et al. 2018; Zaini et al. 2010, Su et al. 2018; Liang et al. 2004; Nowicki and Pietrzak 2011; Chen et al. 2003). The physicochemical properties of such materials depend in significant degree on the quantity and type of heteroatomic functional groups introduced into the carbon matrix by means of different modification. Through introduction of nitrogen, oxygen or sulphur functional species into carbonaceous materials structure is possible to change in large extent their acidic-basic, hydrophobic-hydrophilic character as well as their sorption, catalytic or thermal properties. The effects of functionalization of different carbonaceous materials have been widely reported in many papers (López et al. 2003; Kazmierczak-Razna et al. 2015; Nowicki et al. 2015; Nowicki 2016; Ternero-Hidalgo et al. 2016; Gokce and Aktas 2014; Bhatnagar et al. 2013).

In general, preparation of modified activated carbons is based on conventional heating, which has many drawbacks. An interesting alternative is the use of microwave radiation for this purpose, which is based on conversion of 
electromagnetic energy into thermal energy. In contrast to conventional method, microwave-assisted heating is faster, safer, easier to control and takes place in the entire volume of the sample, so ensures uniform heating of material and accelerates the course of modification process. Taking it into consideration, the main aim of this study was preparation and physicochemical characterization of new carbonaceous materials, obtained by means of nitrogenation, oxidation and thermal treatment of peat-based activated carbon with the use of microwave heating. In order to fully characterize the obtained materials except for obvious ash content analysis, elemental composition of the starting and modified activated carbons, characterization of the pore structure and $\mathrm{pH}$ measurements, coupled method TG/MS (thermogravimetry/mass spectroscopy) and photoacoustic spectroscopy was used.

\section{Experimental}

\subsection{Preparation of modified activated carbons}

At the beginning, the starting peat was subjected to pyrolysis in a quartz tubular reactor heated by horizontal furnace, under a stream of nitrogen blown at the rate of $0.170 \mathrm{~L} / \mathrm{min}$. The sample was heated $\left(10^{\circ} \mathrm{C} / \mathrm{min}\right)$ from room temperature to the final pyrolysis temperature of $600{ }^{\circ} \mathrm{C}$ and maintained for $60 \mathrm{~min}$. After that the obtained char was subjected to physical activation with steam at $800{ }^{\circ} \mathrm{C}$, for $60 \mathrm{~min}$. In order to obtain materials characterised by diverse functional groups content (both in terms of the type and quantity) such prepared activated carbon (denoted as A) was next subjected to four different treatment: (1) oxidation with boiling $25 \%$ solution of nitric acid for $3 \mathrm{~h}$ followed by heat treatment at $600{ }^{\circ} \mathrm{C}$ for $30 \mathrm{~min}$ (denoted as AN), (2) oxidation with $30 \%$ solution of hydrogen peroxide at room temperature for $3 \mathrm{~h}$ followed by heat treatment at $600{ }^{\circ} \mathrm{C}$ for $30 \mathrm{~min}$ (denoted as $\mathrm{AH}),(3)$ annealing in nitrogen atmosphere at $900{ }^{\circ} \mathrm{C}$ for $30 \mathrm{~min}$ (denoted as AT) and (4) impregnation with urea (at the weight ratio of 1:1) followed by heat treatment at $800{ }^{\circ} \mathrm{C}$ for $30 \mathrm{~min}$ (denoted as AU). All the modifications were carried out in a porcelain crucibles heated by microwave muffle furnace Phoenix, provided by CEM Corporation (United States).

\subsection{Sample characterisation}

The ash content for all materials under investigation was determined according to the DNS ISO 1171:2002 standard. Elemental composition of the starting and modified activated carbons was determined using the CHNS Vario EL III analyser (Elementar Analysensysteme $\mathrm{GmbH}$, Germany), whereas the oxygen content was calculated by the difference. Characterization of the pore structure of activated carbons was based on the nitrogen adsorption-desorption measured at $-196{ }^{\circ} \mathrm{C}$ on Autosorb iQ surface area analyser (Quantachrome Instruments, United States). Prior to the isotherm measurements, the samples were out-gassed at $300{ }^{\circ} \mathrm{C}$ for $8 \mathrm{~h}$. BET specific surface area $\left(\mathrm{S}_{\mathrm{BET}}\right)$ was evaluated in the range of relative pressures $\mathrm{p} / \mathrm{p}_{0}$ of $0.05-0.30$. Total pore volume $\left(\mathrm{V}_{\mathrm{t}}\right)$ was calculated by converting the amount adsorbed at $\mathrm{p} / \mathrm{p}_{0} \sim 0.99$ to the volume of liquid adsorbate. Average pore diameter $(D)$ was calculated from equation $D=4 V / / S_{\mathrm{BET}}$. Pore size distribution was calculated from the adsorption branches of isotherms, using the $\mathrm{BJH}$ method. Micropore volume $\left(\mathrm{V}_{\mathrm{m}}\right)$ and area $\left(\mathrm{S}_{\text {micro }}\right)$ were determined by the t-plot method. To estimate the content of surface functional groups of acidic and basic character the Boehm method was applied (Boehm 1994). The $\mathrm{pH}$ measurement was performed using an $\mathrm{pH}$-meter manufactured by Metrohm Ion Analysis (Switzerland), equipped in combined glass $\mathrm{pH}$ electrode with temperature sensor (Unitrode Pt1000), calibrated with standards solutions of $\mathrm{pH} \mathrm{3,7}$ and 10.

Thermal analysis was carried out on a STA 449 Jupiter F1 (Netzsch, Germany) under the following operational conditions: heating rate $10^{\circ} \mathrm{C} / \mathrm{min}$, the dynamic atmosphere of helium $(50 \mathrm{ml} / \mathrm{min})$ in the temperature range of $25-1000{ }^{\circ} \mathrm{C}$, sample mass of about $5 \mathrm{mg}$, sensor thermocouple type $\mathrm{S}$ TGDTA. As a reference, empty $\mathrm{Al}_{2} \mathrm{O}_{3}$ crucible was used. The volatile products coming out during decomposition process were detected by quadrupole mass spectrometer QMS 403C Aëolos (Netzsch, Germany) coupled on-line to STA instrument. The mass spectrometer was connected on-line to STA instrument by quartz capillary heated to $300^{\circ} \mathrm{C}$. The QMS was operated with an electron impact ionizer with energy $70 \mathrm{eV}$. The measurements performed in scan mode for $\mathrm{m} / \mathrm{z}$, where $\mathrm{m}$ is the mass of molecule and $\mathrm{z}$ is a charge of the molecule in electron charge units in the range from 10 to $110 \mathrm{amu}$ allowed to identify all possible volatile particles produced during the decomposition.

The photoacoustic (PAS) spectra were recorded by means of Bio-Rad Excalibur FT-IR 3000 MX spectrometer equipped in with MTEC Model 300 photoacoustic cell, over the $4000-400 \mathrm{~cm}^{-1}$ range at room temperature, resolution $4 \mathrm{~cm}^{-1}$ and maximum source aperture. Dry helium was used to purge the PAS cell before data collection. The spectrum was normalized by computing the ratio of a sample spectrum to the spectrum of a MTEC carbon black standard. A stainless steel cup (diameter $10 \mathrm{~mm}$ ) was filled with sample (thickness $<6 \mathrm{~mm}$ ). Interferograms of 1024 scans were averaged for the spectrum, providing good signal-to-noise $(\mathrm{S} / \mathrm{N})$ ratio. All samples were dried in $115^{\circ} \mathrm{C}$ for $48 \mathrm{~h}$. 
Table 1 Elemental composition of activated carbons (wt\%)

\begin{tabular}{lllllll}
\hline Sample & Ash & $\mathrm{C}^{\text {daf }}$ & $\mathrm{H}^{\text {daf }}$ & $\mathrm{N}^{\text {daf }}$ & $\mathrm{S}^{\text {daf }}$ & $\mathrm{O}^{\text {diff }}$ \\
\hline A & 7.5 & 94.3 & 0.6 & 0.5 & 0.2 & 4.4 \\
AN & 7.1 & 92.2 & 1.2 & 0.9 & 0.1 & 5.6 \\
AH & 7.7 & 94.9 & 0.9 & 0.7 & 0.1 & 3.4 \\
AT & 8.3 & 96.3 & 0.6 & 0.6 & 0.2 & 2.3 \\
AU & 8.4 & 95.7 & 0.7 & 1.7 & 0.2 & 1.8 \\
\hline
\end{tabular}

daf dry-ash-free basis, diff calculated by difference
Table 2 Acidic-basic properties of the activated carbons

\begin{tabular}{lrlll}
\hline Sample & $\mathrm{pH}$ & $\begin{array}{l}\text { Acidic groups } \\
(\mathrm{mmol} / \mathrm{g})\end{array}$ & $\begin{array}{l}\text { Basic groups } \\
(\mathrm{mmol} / \mathrm{g})\end{array}$ & $\begin{array}{l}\text { Total } \\
\text { content } \\
(\mathrm{mmol} / \mathrm{g})\end{array}$ \\
\hline $\mathrm{A}$ & 7.51 & 0.24 & 0.33 & 0.57 \\
$\mathrm{AN}$ & 7.72 & 0.60 & 0.68 & 1.28 \\
$\mathrm{AH}$ & 9.43 & 0.46 & 0.62 & 1.08 \\
$\mathrm{AT}$ & 10.57 & 0.20 & 0.93 & 1.13 \\
$\mathrm{AU}$ & 9.90 & 0.45 & 0.73 & 1.18 \\
\hline
\end{tabular}

\section{Results and discussion}

As follow from the data presented in Table 1 the starting peat-based activated carbon is characterised by very high $\mathrm{C}^{\text {daf }}$ content (94.3 wt\%), relatively high amount of mineral matter (7.5 wt $\%)$ and small admixture of non-carbon organic components, mainly oxygen. As seen, each of the modifications carried out caused significant changes in the chemical composition of starting material. These changes are most evident in case of AU and AN samples. Sample prepared by reaction with urea followed by thermal treatment at $800{ }^{\circ} \mathrm{C}(\mathrm{AU})$ shows the highest nitrogen and simultaneously the lowest oxygen content among the investigated carbon materials. In turn, in structure of AN sample (prepared by means of nitric acid oxidation followed by heat treatment at $600{ }^{\circ} \mathrm{C}$ ), the lowest carbon content and the highest contribution of oxygen was found. Other variants of thermo-chemical treatment cause a slight increase in the $\mathrm{C}^{\text {daf }}$ contribution and slight changes in the content of hydrogen and heteroatoms. These changes are most probably a consequence of gasification of least stable fragments of carbonaceous structure as well as progressing aromatisation of carbon matrix during heat treatment.

According to the data presented in Table 2 all modifications lead also to significant changes in acid-base properties of the peat-based activated carbon. As a result of thermochemical treatment the total content of surface functional groups increase, in particular for AN sample, which contain almost three times more groups of acidic character as well as twice more basic surface groups than unmodified carbon (A). In turn, the AT sample, received by means of annealing of starting activated carbon in nitrogen atmosphere is characterised by the highest content $(0.93 \mathrm{mmol} / \mathrm{g})$ and simultaneously the greatest prevalence of basic functional groups (almost five times) over acidic ones, what is also confirmed by very high $\mathrm{pH}$ value (10.57). This is most probably a consequence of high temperature of annealing $\left(900^{\circ} \mathrm{C}\right)$, which favours formation of greater amount of functional groups of basic nature as well as leads to a decomposition of the majority of acidic groups present on carbon surface. In case of samples subjected to thermal treatment in milder conditions (AH, AU and especially $\mathrm{AN}$ ) the dominance of basic functional groups is definitely smaller.

As indicated by the data collected in Table 3 and in Figs. 1 and 2, all the samples under investigation show very similar textural parameters, independent on variant of modification. They have medium-developed surface area ranging from 582 to $657 \mathrm{~m}^{2} / \mathrm{g}$ and porous structure with dominant mesopores. The most developed surface area of $657 \mathrm{~m}^{2} / \mathrm{g}$ was found for sample AN oxidised with $\mathrm{HNO}_{3}$ and subjected to thermal treatment in microwave furnace at $600{ }^{\circ} \mathrm{C}$,
Table 3 Textural parameters of activated carbons

\begin{tabular}{|c|c|c|c|c|c|c|}
\hline \multirow[t]{2}{*}{ Sample } & \multicolumn{2}{|c|}{ Surface area $\left(\mathrm{m}^{2} / \mathrm{g}\right)$} & \multicolumn{2}{|c|}{ Pore volume $\left(\mathrm{cm}^{3} / \mathrm{g}\right)$} & \multirow[t]{2}{*}{$\mathrm{V}_{\mathrm{m}} / \mathrm{V}_{\mathrm{t}}$} & \multirow[t]{2}{*}{$\mathrm{D}(\mathrm{nm})$} \\
\hline & Total & Micropore & Total & Micropore & & \\
\hline A & 596 & 395 & 0.78 & 0.21 & 0.28 & 5.23 \\
\hline AN & 657 & 458 & 0.72 & 0.25 & 0.35 & 4.43 \\
\hline $\mathrm{AH}$ & 619 & 402 & 0.73 & 0.22 & 0.30 & 4.73 \\
\hline AT & 607 & 414 & 0.69 & 0.22 & 0.32 & 4.58 \\
\hline $\mathrm{AU}$ & 582 & 376 & 0.71 & 0.20 & 0.29 & 4.89 \\
\hline
\end{tabular}

$\mathrm{V}_{\mathrm{m}} / \mathrm{V}_{\mathrm{t}}$, micropore contribution 
Fig. 1 Nitrogen adsorption/ desorption isotherms of the activated carbons

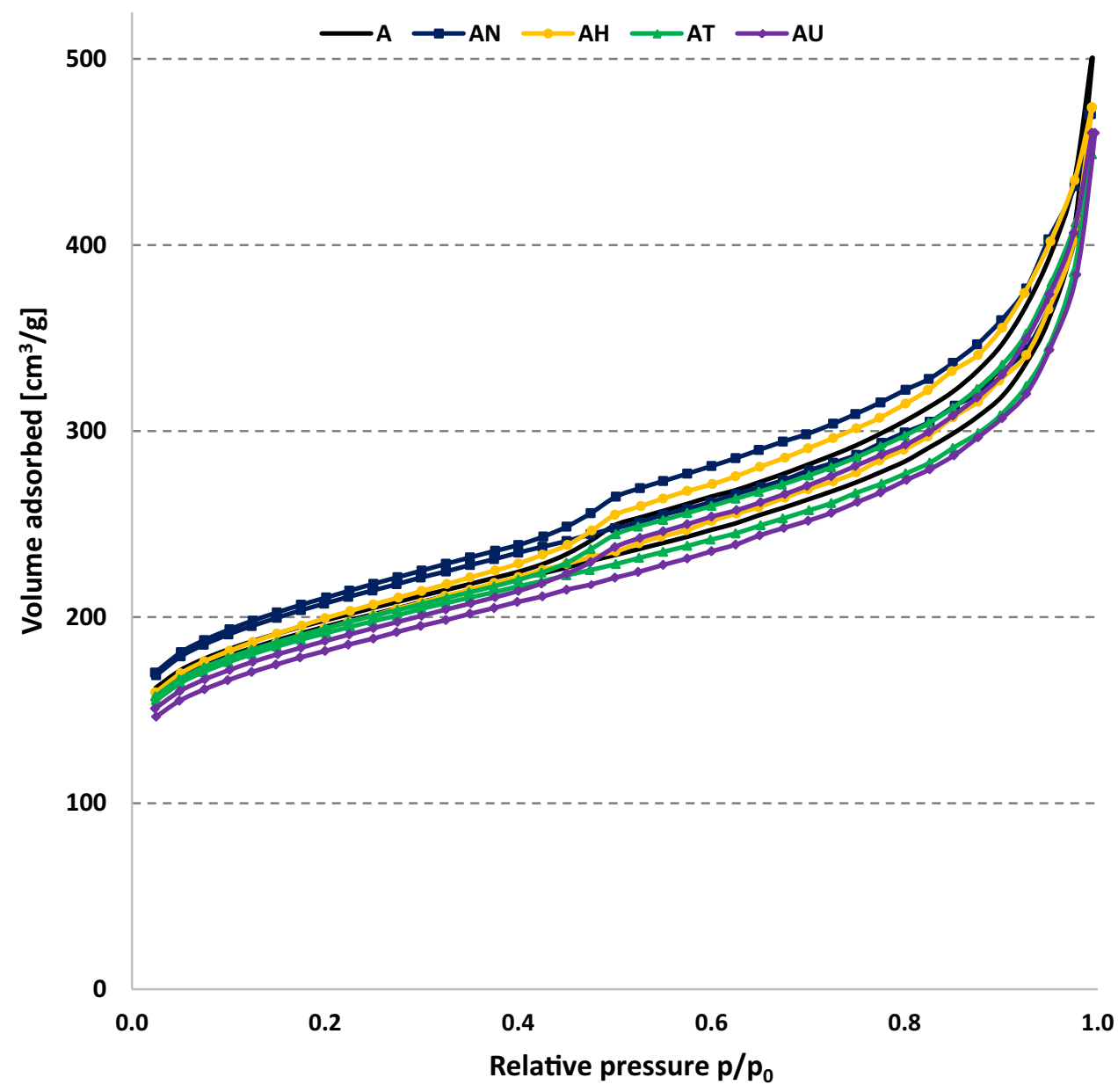

Fig. 2 Pore size distribution of the activated carbons

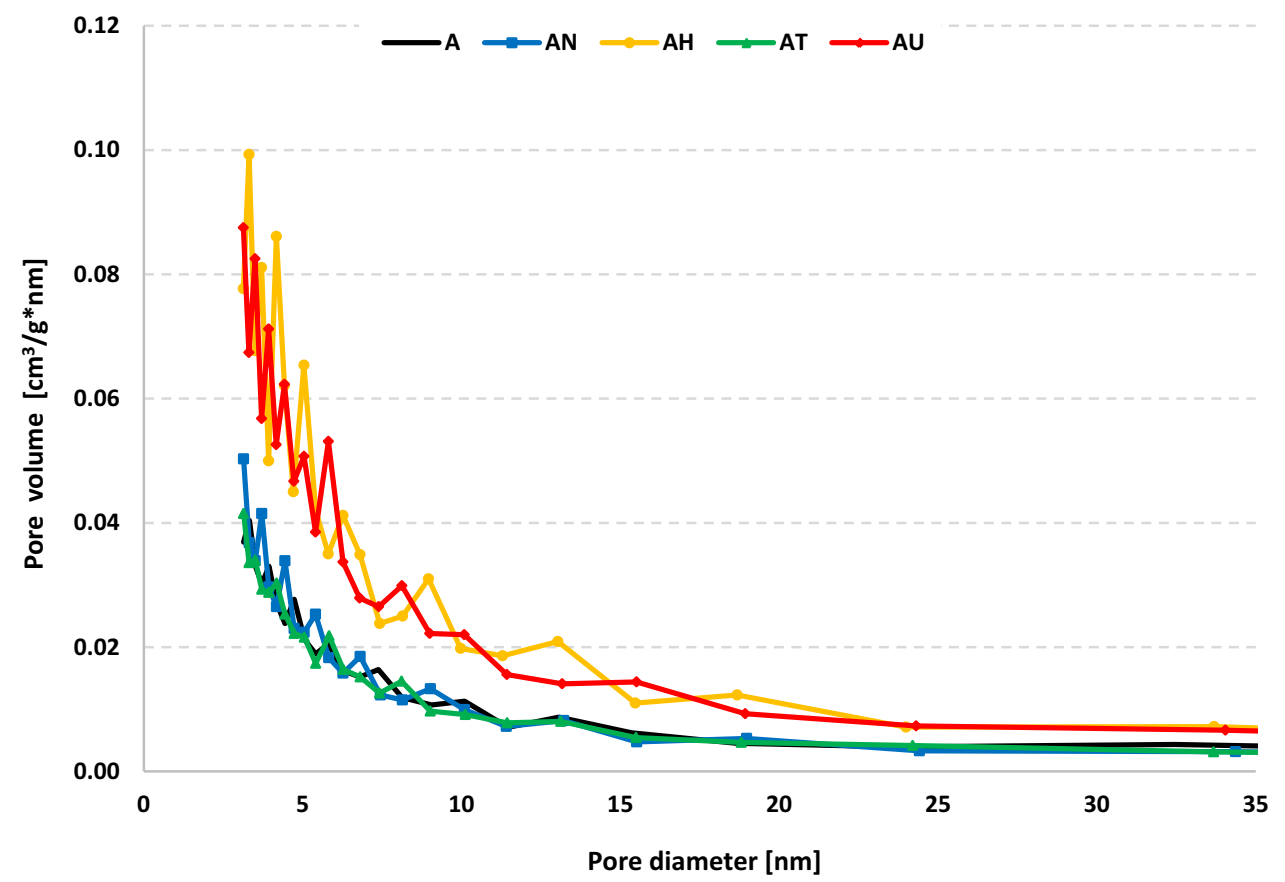


while the greatest total pore volume of $0.78 \mathrm{~cm}^{3} / \mathrm{g}$ as well as the most mesoporous character of texture was found for unmodified activated carbon (A). As follows from further analysis of the textural data, modification of starting activated carbon led to generation of some new micropores in its porous structure. This process is most effective in case of AN and AT samples, for which the micropore contribution in total pore volume is by 7 and $4 \%$ higher than for unmodified carbon. It is also confirmed by narrower average pore diameter in comparison to $\mathrm{AH}, \mathrm{AU}$ and particularly to starting activated carbon.

According to the IUPAC classification, the isotherms obtained for all prepared carbons (Fig. 1) belong to type $\mathrm{IV}$, which is characteristic for micro/mesoporous materials. In the range of relative pressure between 0 and $\sim 0.45$ the adsorption branch of isotherm increase slowly, what indicates the mono- and multi-molecular layer sorption in micro and mesopores. Further increase of relative pressure causes a capillary condensation in mesopores, what is evidenced by wide hysteresis loop, similar to $\mathrm{H} 3$ type. In turn, the lack of the horizontal plateau as well as a rapid increase in adsorption capacity at $\mathrm{p} / \mathrm{p}_{0}$ close to 1 , suggest that the samples studied have also some amount of macropores. As follows from the course of pore size distribution curves presented in Fig. 2, the main contribution in the porous structure of carbons studied have mesopores with diameters in the range between 3 and $12 \mathrm{~nm}$.

All tested samples were subjected also to thermal and spectroscopic analysis. By using coupled methods, we can get in one analysis, multiple data. Based on thermal studies we get information about thermal stability, how the mass loss is changing during the temperature increase and based on the curve slop we can estimate the tendency of the samples degradation. Activated carbon obtained via physical activation of peat with steam at $800{ }^{\circ} \mathrm{C}$ - sample A-is thermally stable up to $545^{\circ} \mathrm{C}$ (recorded mass loss $2.5 \mathrm{wt} \%$ ). Sample AU, which was subjected to impregnation with urea followed by heat treatment at $800{ }^{\circ} \mathrm{C}$ has almost identical thermal stability (Figs. 3, 4). Annealing in nitrogen atmosphere at $900{ }^{\circ} \mathrm{C}$ or subjecting sample A to oxidation with $25 \%$ solution of nitric acid followed by heat treatment at $600{ }^{\circ} \mathrm{C}$ enhance the thermal stability, while oxidation with $30 \%$ solution of hydrogen peroxide followed by heat treatment at $600{ }^{\circ} \mathrm{C}$ diminishes it. But, it should be noted that sample AN, after reaching temperature of $580{ }^{\circ} \mathrm{C}$ (recorded mass loss of $2.4 \mathrm{wt} \%$ ) begins to lose mass very quickly. Nevertheless, the sample annealed in nitrogen atmosphere (AT) is the most stable sample. This is most likely related to the incorporation of nitrogen atoms into the surface carbon layers. Carbons with built-in nitrogen atoms have greater thermal stability (Jankowska et al. 1991). When discussing thermal stability, one should take into account the changes that occur at the beginning of the temperature rise. Figures 5 and 6 shows the changes of intensity of ions m:17 and m:18 which are responsible to the presence of hydroxyl groups and water. Their presence are also visible on Fig. 4, where observed maximum on DTG curves around $40{ }^{\circ} \mathrm{C}$ is due to the desorption of the physically absorbed water. By subjecting the material to oxidation process, its surface will acquire a strong hydrophilic character, which will cause strong water sorption. As it shown in Table 1 sample AN is characterized by a high oxygen content, which is also confirmed by MS spectroscopy (Figs. 5, 6) by relatively high content of water and hydroxyl groups. It should be also noted that in the case
Fig. 3 TG curves of the activated carbons

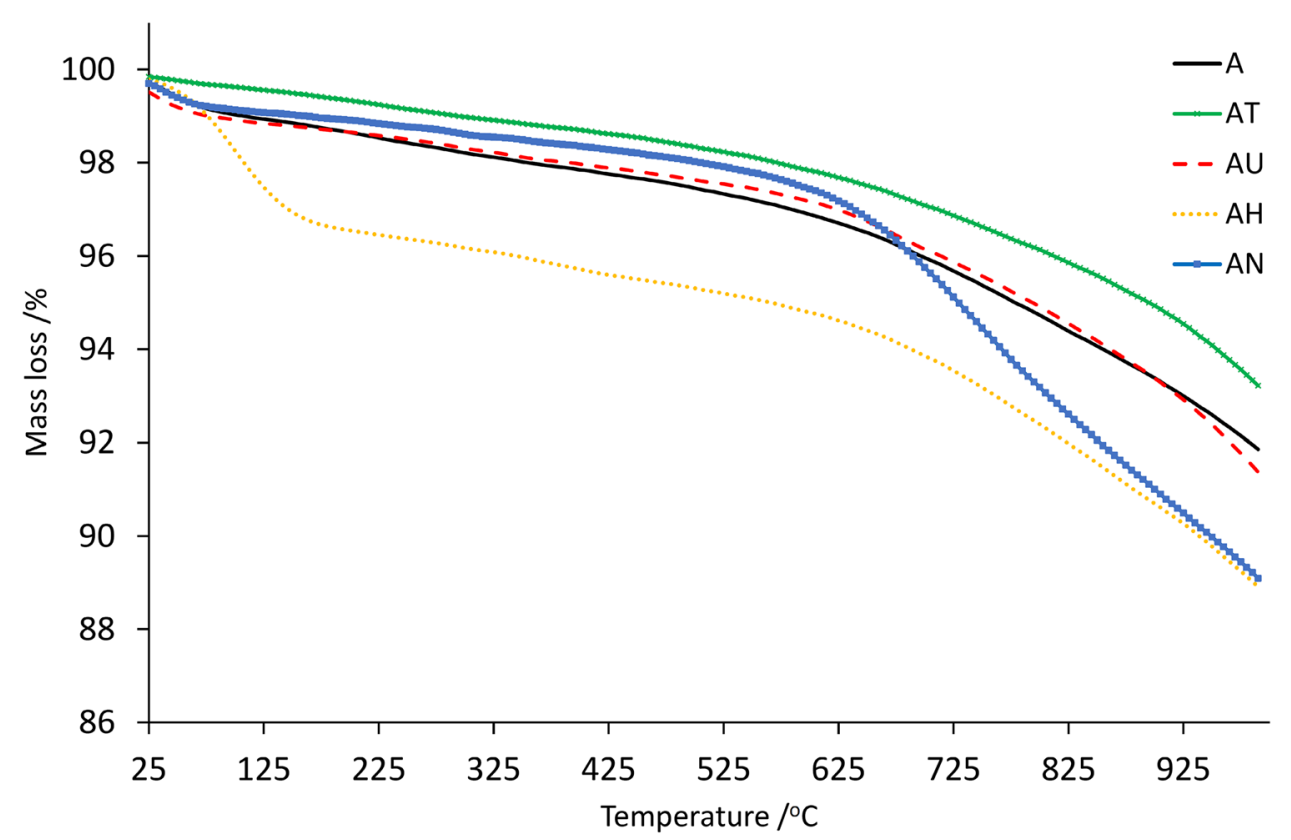


Fig. 4 DTG curves of the activated carbons

Fig. 5 Temperature distribution of ion $\mathrm{m}: 17$
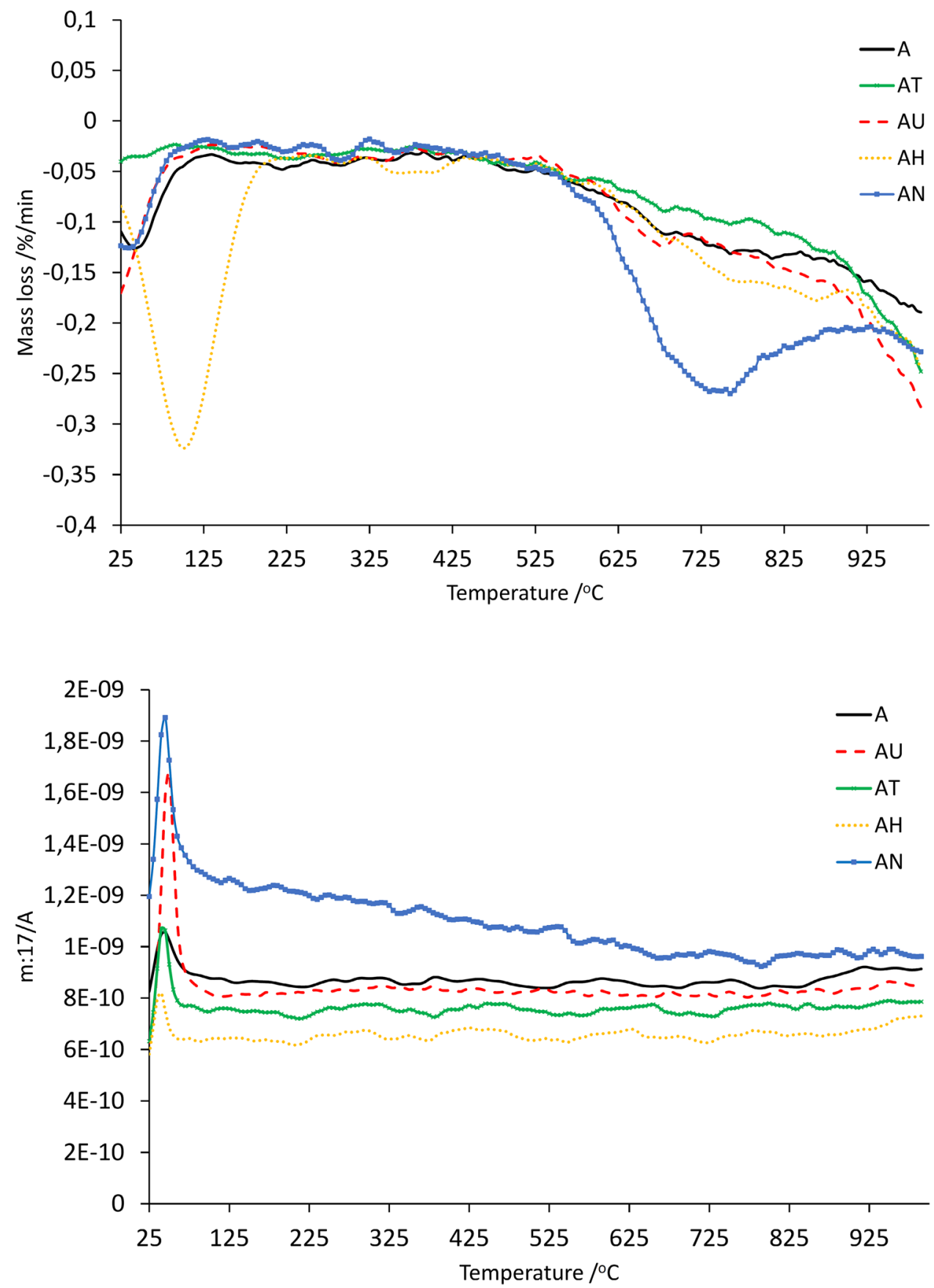

of sample AU (which was subjected to impregnation with urea), the presence of ions: 17 and 18 can also suggest the presence of ammonia and ammonium.

By looking at the Figs. 3 and 4 it can be certainly stated that the sample $\mathrm{AH}$ has the lowest thermal stability. At the very beginning of the temperature rise, a large mass loss of $3.3 \mathrm{wt} \%$ till $190{ }^{\circ} \mathrm{C}$ is noticeable (DTG curve maximum recorded at $100{ }^{\circ} \mathrm{C}$ ). At this temperature, the mass loss is no longer so rapid. This mass loss is not only related to the presence to ions: 17 and 18 but also to the presence to ions: 29, 41, 42, 43 (which are only recorded for this sample) (Fig. 7).
These ions are most likely responsible for the presence of the following groups: $\mathrm{CHO}, \mathrm{CH}_{3} \mathrm{CN}, \mathrm{NCO}(+\mathrm{H})$. Presented data indicate, that the carbon surface was successfully oxidized. Based on data collected in Fig. 8 it can be concluded, that all tested sample around temperature of $525^{\circ} \mathrm{C}$ starts to emit ion: 44, which probably is responsible for the presence of carboxyl group.

The FT-IR spectra of the samples in the region of $\mathrm{C}-\mathrm{H}$ and $-\mathrm{OH}$ groups are presented in Fig. 9. There are no bands indicating the presence of $\mathrm{C}-\mathrm{H}\left(-\mathrm{CH}_{2}\right.$ or $\left.-\mathrm{CH}_{3}\right)$ groups in the carbon material. The intense band in the 
Fig. 6 Temperature distribution of ion $\mathrm{m}: 18$
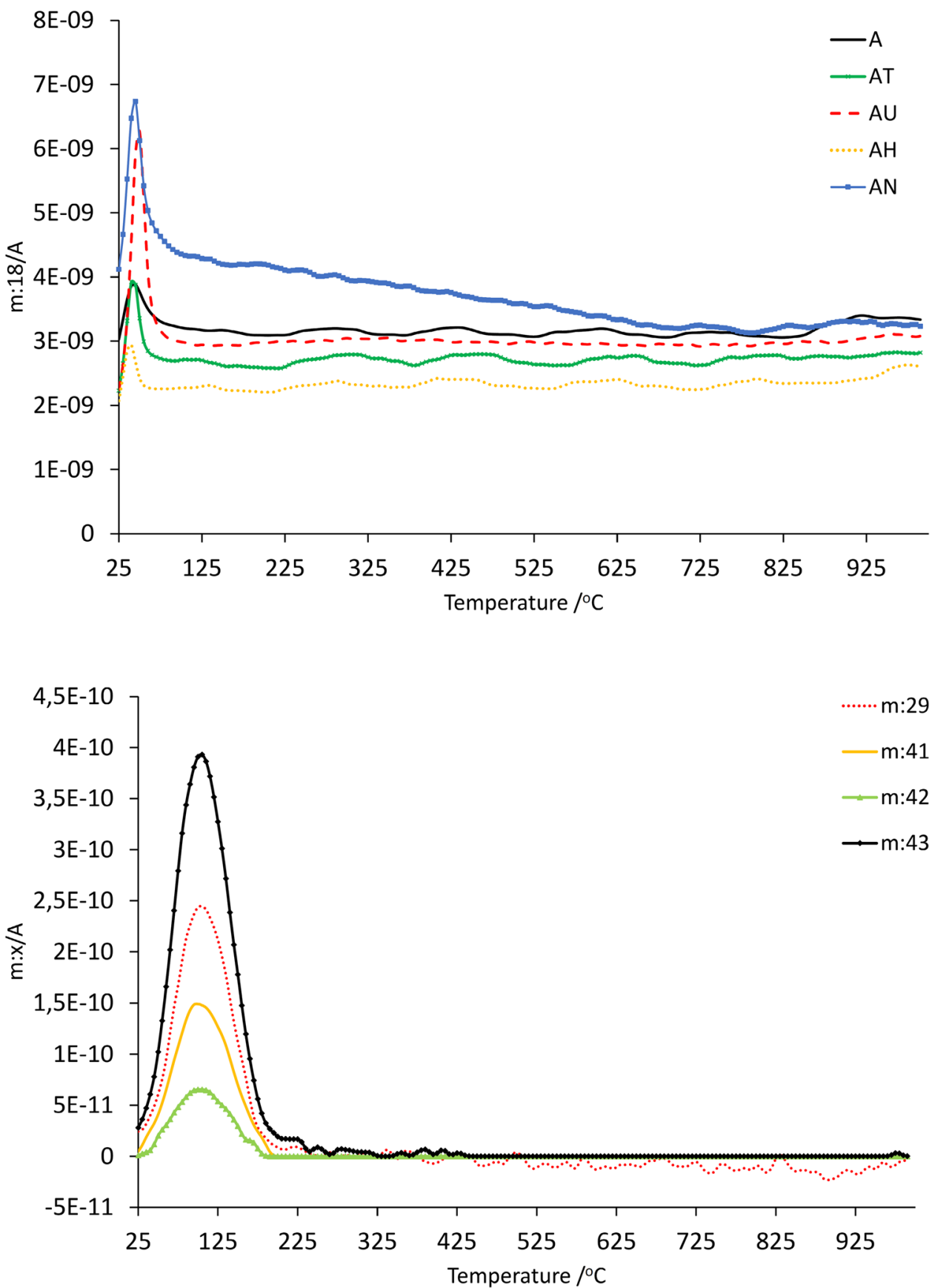

Fig. 7 Temperature distribution of ions m: 29, 41, 42, 43 for sample $\mathrm{AH}$
$2400-2300 \mathrm{~cm}^{-1}$ range indicates the presence of the carbonization product, namely carbon dioxide, which is probably trapped in the carbon structure and not removed during drying. The band of $\mathrm{CO}_{2}$ is visible also in $700-600 \mathrm{~cm}^{-1}$ range (peak at $~ 680 \mathrm{~cm}^{-1}$, Fig. 10), but only in AT, AH and AN samples spectra. In the case of other samples, the peak of $\mathrm{CO}_{2}$ is inverse $\left(2400-2300 \mathrm{~cm}^{-1}\right)$ and there is no peak visible at $\sim 680 \mathrm{~cm}^{-1}$. This is probably due to the fact that there is less $\mathrm{CO}_{2}$ remained in the pores of these carbon samples that is in carbon black standard (used for background collection).
The fingerprint region is the most suitable for oxygen groups identification (Fig. 10), although all bands in this region have relatively low intensity. Region below $1300 \mathrm{~cm}^{-1}$ is difficult to interpret in detail because $\mathrm{C}-\mathrm{O}$ stretching modes (ethers, esters, alcohols), as well as $\mathrm{C}-\mathrm{OH}$ bending modes (alcohols, amides) absorb in the same frequency range. The bands below $1050 \mathrm{~cm}^{-1}$ may also have inorganic compounds contribution (i.e. silica and other inorganic compounds), which is caused by their presence in the starting material (peat moss). These modes are coupled with other vibrations and do not exhibit well defined 
Fig. 8 Temperature distribution of ion $\mathrm{m}: 44$

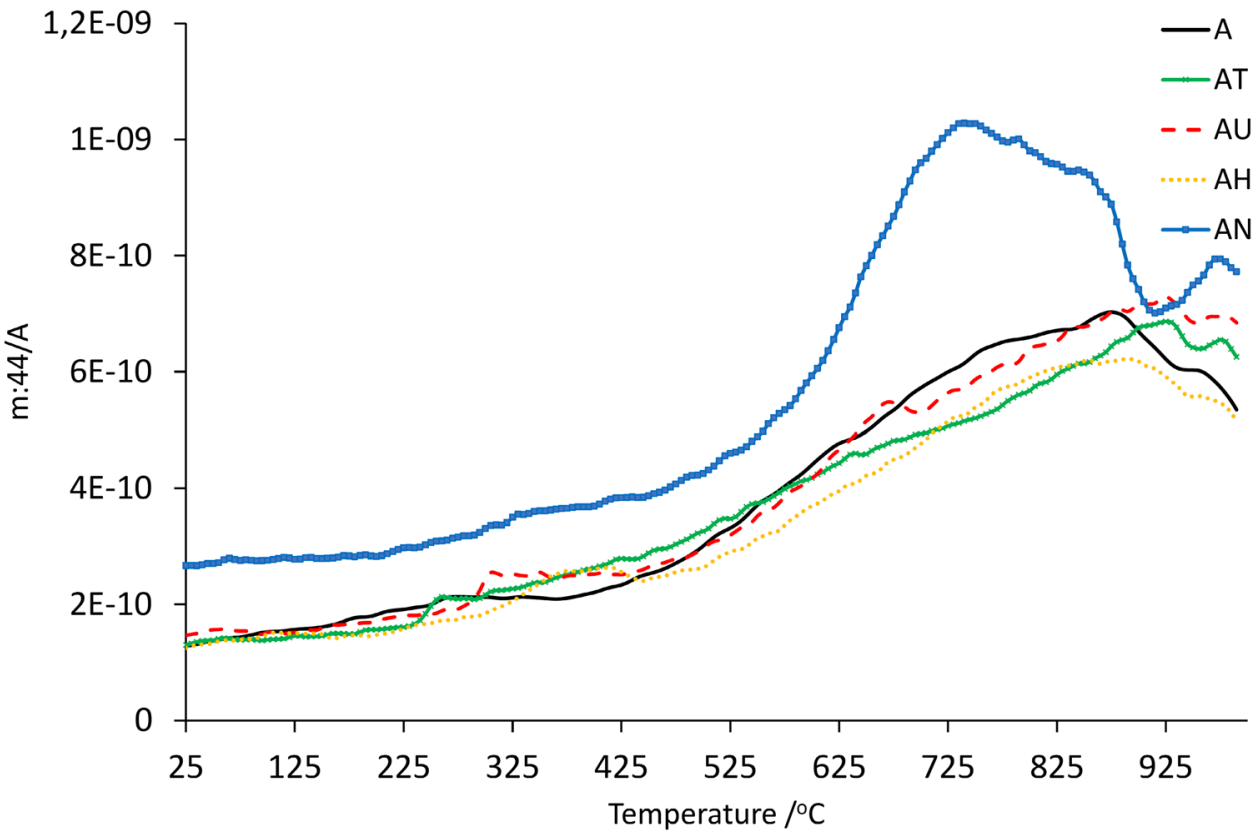

Fig. 9 FT-IR/PAS spectra of examined samples in the $3500-2000 \mathrm{~cm}^{-1}$ range

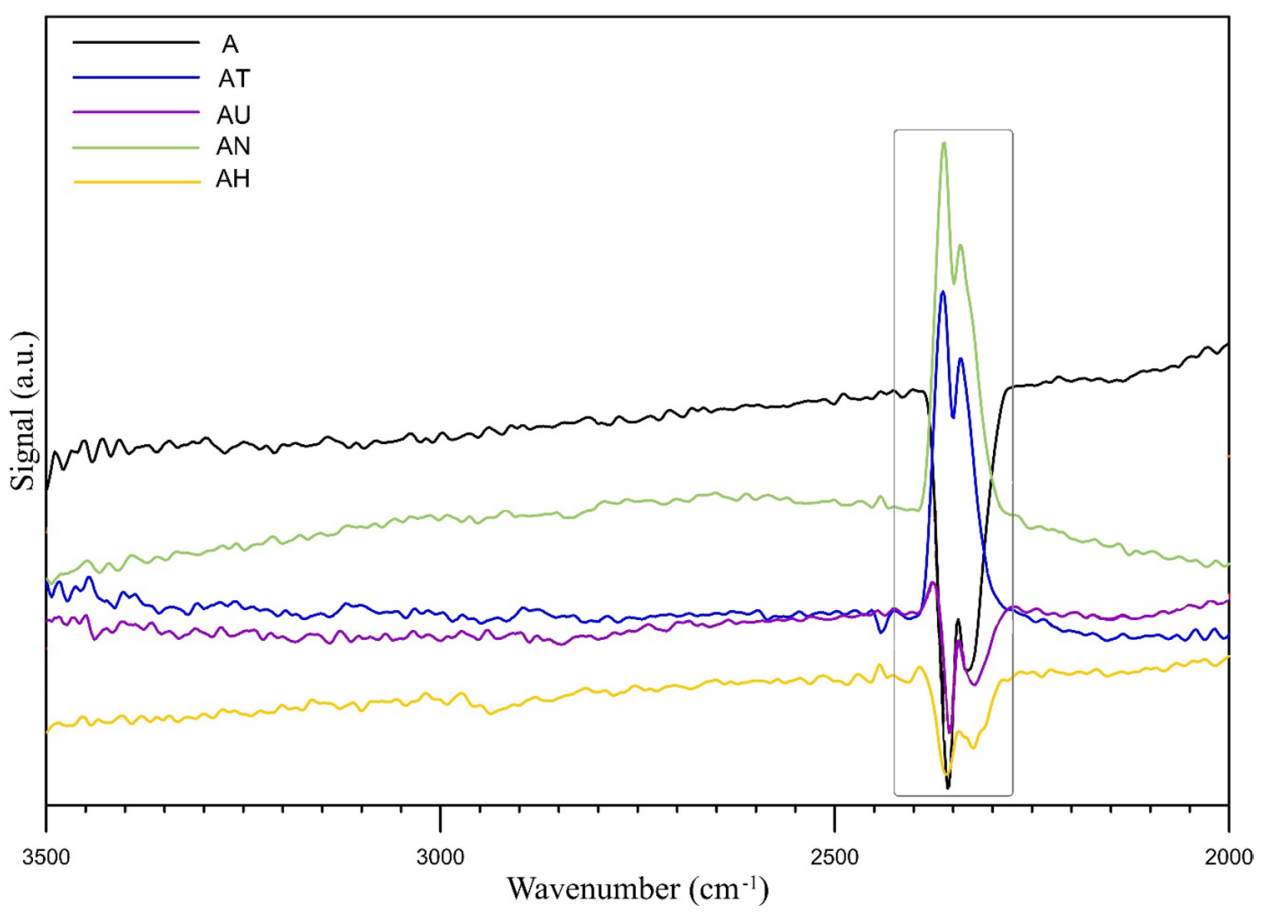

group frequencies (Bellamy 1980). Some assignments are nevertheless possible. The bands at 1218, 1145, 1084, 570, 535 and $495 \mathrm{~cm}^{-1}$ could be due to $\mathrm{C}-\mathrm{O}$ and $\mathrm{C}-\mathrm{O}-\mathrm{C}$ in ether structures and/or $\mathrm{C}=\mathrm{C}$ stretching in aromatic structures (C-C skeleton vibrations) (Gomez-Serrano et al. 1999). The intensities of those peaks are the lowest in the case of A and AU samples. The band at $\sim 930 \mathrm{~cm}^{-1}$, absent in A and AU samples, may be attributed to $\mathrm{N}-\mathrm{O}$ stretching in oximes or out-of-plane deformation vibration in $-\mathrm{COOH}$ groups
(Socrates 2001). Additional band at $1461 \mathrm{~cm}^{-1}$, which is present only in AH sample spectra, indicate the presence of $\mathrm{C}-\mathrm{C}=\mathrm{O}$ in-plane deformation vibration of $-\mathrm{COOH}$ groups present on the samples surface (Socrates 2001). Unfortunately, this cannot be confirmed by analysing the spectra above $1400 \mathrm{~cm}^{-1}$ (not shown) due to the wide, ragged band in the range of $1450-1850 \mathrm{~cm}^{-1}$ (hydrogen bonded $\mathrm{O}-\mathrm{H}$ stretching vibrations; unremoved water). The PAS spectra have also inverse peaks (about $1050-1000 \mathrm{~cm}^{-1}$ ), the 
Fig. 10 FT-IR/PAS spectra of examined samples in the $1400-400 \mathrm{~cm}^{-1}$ range

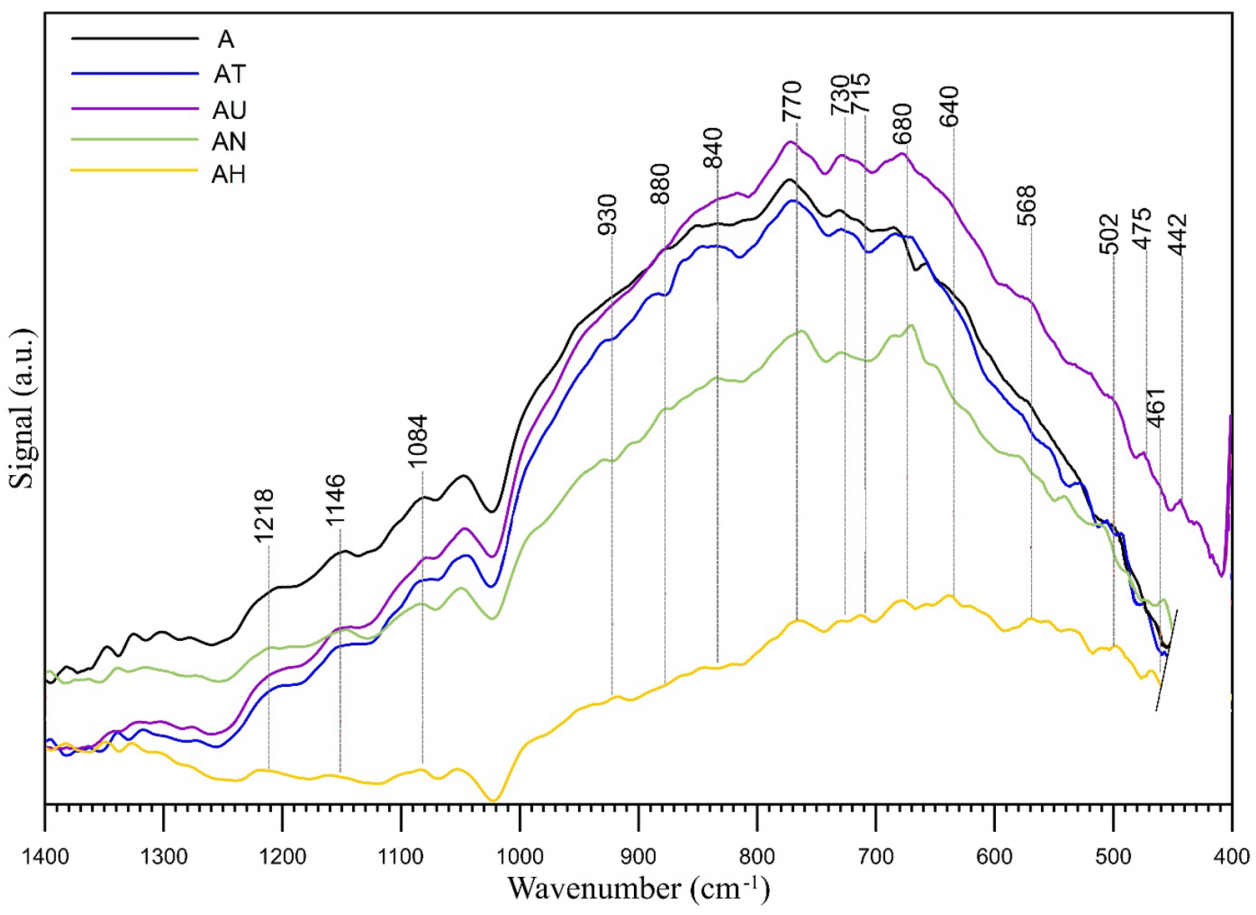

presence of which is probably due to the fact that the carbon black standard used for normalizing the PAS spectra has higher intensity of bands in this range than the analysed sample. Nevertheless, the presence of oxygen functional groups in analysed region indicates that the modification with oxidizing agents was effective, although the amount of these groups is very small, most probably as a consequence of further thermal treatment in microwave furnace.

\section{Conclusions}

The above-discussed results have proved that, application of different variants of peat-based activated carbon, such as oxidation, nitrogenation and high temperature treatment with the use of microwave energy, allows to produce a wide panoply of carbonaceous materials, differing significantly in the type of porous structure, chemical composition as well as acid-base character of surface. Moreover, it has been proved that the functional groups introduced into activated carbon structure affect in very high extent its thermal stability. Annealing of the activated carbon in nitrogen atmosphere at $900{ }^{\circ} \mathrm{C}$ or oxidation with $25 \%$ solution of nitric acid followed by heat treatment at $600{ }^{\circ} \mathrm{C}$ enhance the thermal stability of carbonaceous structure, whereas the oxidation with $30 \%$ solution of hydrogen peroxide followed by heat treatment at $600{ }^{\circ} \mathrm{C}$ diminishes it. Based on both mass and photoacoustic spectroscopy the introduction of oxygen functional groups has been proven.
Open Access This article is distributed under the terms of the Creative Commons Attribution 4.0 International License (http://creativeco mmons.org/licenses/by/4.0/), which permits unrestricted use, distribution, and reproduction in any medium, provided you give appropriate credit to the original author(s) and the source, provide a link to the Creative Commons license, and indicate if changes were made.

\section{References}

Bellamy, L.J.: The infrared spectra of complex molecules. Advances in infrared group frequencies, vol. 2. Chapman and Hall, London (1980)

Bhatnagar, A., Hogland, W., Marques, M., Sillanpää, M.: An overview of the modification methods of activated carbon for its water treatment applications. Chem. Eng. J. 219, 499-511 (2013)

Boehm, H.P.: Some aspects of the surface chemistry of carbon blacks and other carbons. Carbon 32(5), 759-769 (1994)

Chen, W.C., Wen, T.C., Teng, H.: Polyaniline-deposited porous carbon electrode for supercapacitor. Electrochim. Acta 48, 641-649 (2003)

Gokce, Y., Aktas, Z.: Nitric acid modification of activated carbon produced from waste tea and adsorption of methylene blue and phenol. Appl. Surf. Sci. 313, 352-359 (2014)

Gomez-Serrano, V., Piriz-Almeida, F., Duran-Valle, C.J., Pastor-Villegas, J.: Formation of oxygen structures by air activation. A study by FT-IR spectroscopy. Carbon 37, 1517-1528 (1999)

Huang, C.C., Chen, C.H., Chu, S.H.: Effect of moisture on $\mathrm{H}_{2} \mathrm{~S}$ adsorption by copper impregnated activated carbon. J. Hazard. Mater. 136, 866-873 (2006)

Jankowska, H., Świątkowski, A., Starostin, L., ŁawrinienkoOmiecyńska, J.: Adsorpcja jonów na węglu aktywnym. PWN, Warszawa (1991)

Kazmierczak-Razna, J., Nowicki, P., Pietrzak, R.: The use of microwave radiation for obtaining activated carbons enriched in nitrogen. Powder Technol. 273, 71-75 (2015) 
Liang, Ch, Wei, Z., Xin, Q., Li, C.: Ammonia - treated activated carbon as support of a Ru-Ba catalyst for ammonia synthesis. React. Kinet. Catal. Lett. 83, 39-45 (2004)

López, F., Medina, F., Prodanov, M., Güell, C.: Oxidation of activated carbon: application to vinegar decolorization. J. Coll. Int. Sci. 257, 173-178 (2003)

Nowicki, P.: Effect of heat treatment on the physicochemical properties of nitrogen-enriched activated carbons. J. Therm. Anal. Calorim. 125, 1017-1024 (2016)

Nowicki, P., Pietrzak, R.: Effect of ammoxidation of activated carbons obtained from sub-bituminous coal on their $\mathrm{NO}_{2}$ sorption capacity under dry conditions. Chem. Eng. J. 166, 1039-1043 (2011)

Nowicki, P., Kazmierczak, J., Sawicka, K., Pietrzak, R.: Nitrogenenriched activated carbons prepared by the activation of coniferous tree sawdust and their application in the removal of nitrogen dioxide. Int. J. Environ. Sci. Technol. 12, 2233-2244 (2015)

Severa, G., Head, J., Bethune, K., Higgins, S., Fujise, A.: Comparative studies of low concentration $\mathrm{SO}_{2}$ and $\mathrm{NO}_{2}$ sorption by activated carbon supported $\left[\mathrm{C}_{2} \mathrm{mim}\right][\mathrm{Ac}]$ and $\mathrm{KOH}$ sorbents. J. Environ. Chem. Eng. 6, 718-727 (2018)
Socrates, G.: Infrared and raman characteristic group frequencies. tables and charts. Wiley, Chichester (2001)

Su, W., Yao, L., Ran, M., Sun, Y., Liu, J., Wang, X.: Adsorption properties of $\mathrm{n}_{2}, \mathrm{ch}_{4}$, and $\mathrm{co}_{2}$ on sulfur-doped microporous carbons. J. Chem. Eng. Data 63(8), 2914-2920 (2018)

Ternero-Hidalgo, J.J., Rosas, J.M., Palomo, J., Valero-Romero, M.J., Rodríguez-Mirasol, J., Cordero, T.: Functionalization of activated carbons by $\mathrm{HNO}_{3}$ treatment: Influence of phosphorus surface groups. Carbon 101, 409-419 (2016)

Zaini, M.A., Amano, Y., Machida, M.: Adsorption of heavy metals onto activated carbons derived from polyacrylonitrile fiber. J. Hazard. Mater. 180(1-3), 552-560 (2010)

Publisher's Note Springer Nature remains neutral with regard to jurisdictional claims in published maps and institutional affiliations. 